\title{
Garcilaso y Fray Luis de León: coincidencias temáticas y contraste de actitudes
}

Hace casi cuarenta años el estudio de la tradición literaria culta se renovó con la atención concédida a los lugares comunes, que tuvo su más brillante paladín en Ernst Robert Curtius. La topística por él capitaneada 'se ocupäba principalmente de temas, motivos y formaś de expresión que, desde los clásicos de la antigüedad o desde los modelos de la latinidad medieval, han perdurado en las literaturas europeas: Variante de la topística, con mayor amplitud de miras y mayor trascendencia en los problemas planteados, es el estudio de la herencia que una literatura y espíritu nacionales hayan recibido de una tradición ideológica y artística más amplia: es la orientación que, para las letras españolas, está representada por Spain and the Western Tradition de Otis $\mathrm{H}$. Green. Ahora bien, junto a la idea de continuidad, dominante en ambos tipos de investigación y que responde a réalidades innegables, cabe el enfoque complementario: poner de relieve la incesante modificación que vivifica la tranmisión tradicional e impide que se fosilice. Temas seculares, lugares comunes, fórmulas expresivas previamente acuñadas, ideas procedentes de un legado cultural, pueden cambiar de sentido cuando se ponen al servicio de una nueva concepción del mundo o de una actitud vital distinta. Asimismo pueden ofrecer significación diferente según el temple de cada autor y según sus circunstancias biográficas y am- 
bientales. En realidad todo estudio de literatura comparada, o de influencias de un autor sobre otro, lleva en sí la necesidad de señalar contrastes. Hoy pretendo contraponer el tratamiento de un mismo tema en dos poetas españoles, Garcilaso y Fray Luis de León. A pesar de que la distancia temporal que los separa no llega al medio siglo y a pesar de las evidentes reminiscencias garcilasianas que hay en Fray Luis, los pasajes de cada uno llevan a mundos espirituales diversos.

A primera vista la contraposición sería simplemente la que enfrenta la Contrarreforma al Renacimiento. Es cierto que cuando hablamos de Garcilaso como el más caracterizado poeta renacentista español, solemos olvidar que en su obra la alegría vital del Renacimiento sólo aparece sin reservas en contadas ocasiones. Lo normal es la melancolía, el «dolorido sentir" inalienable. Es que en la poesía española Garcilaso es inaugural; pero dentro del Renacimiento, no. Cuando él florece, hace mucho que han pasado las invitaciones de Lorenzo de'Medici al goce despreocupado: frente al "Quant'è bella giovinezza / che si fugge tuttavia! / Chi vuoi esser lieto, sia: / del doman non c'è certezza», el soneto XXIII de Garcilaso se dirige a una dama cuyo mirar es a la vez ardiente $y$. honesto, "enciende el corazón y lo refrena»; y Garcilaso no habla de fúturo incierto, sino de viento helado que marchitará las rosas con las mudanzas de la edad. Han pasado también Poliziano y Ariosto. Las hijas del virrey de Nápoles, las presuntas ninfas de la. Egloga III, fueron retratadas por un manierista, el Bronzino, pintor de la vida interior y los impulsos contenidos. Al tiempo que Garcilaso escribía en Nápoles, Juan de Valdés orientaba allí la religiosidad de sus adeptos hacia la iluminación interior y la confianza salvadora. Entre sus seguidores habia ilustres damas, por lo que Menéndez Pelayo le llamó malignamente "evangelizador de princesas». Una de ellas, Vittoria Colonna, fue también retratada por el Bronzino: el cuadro, conservado en el Museo de San Francisco, en California, la muestra ya vieja y leyendo en su libro de horas el salmo "I. - T e, Dom ine, speravi". En 1536, el año en que Garcilaso muere, aparecía impresa la Poética, de Aristóteles, eje en torno al cual habían de girar las doctrinas literarias del manierismo. En España, Carlos V, tras el saqueo de Roma, se 
dejaba defender por.los argumentos de su secretario; el erasmista Alfonso de Valdés, hermano de Juan. Había quienes abrigaban la ilusión de que el César restaurase la unidad de la Iglesia. Pero la actitud de las órdenes religiosas auguraba la próxima caída del erasmismo; se procesaba a los alumbrados, y como tal, Juan de Valdés había tenido ya que emigrar a Italia. Garcilaso escribe, pues, cuando los resplandores del Renacimiento empezaban a ensombrecerse.

Entre el nacimiento de Garcilaso y el de Fray Luis de León median veinticuatro o veintiséis años; transcurrieron cuarenta desde la muerte de Garcilaso hasta que Fray Luis fue puesto en libertad después de su primer proceso inquisitorial. Estos años fueron decisivos: durante ellos Carlos V había visto fracasar a la vez sus intentos de concordia religiosa y sus sueños de imperio europeo; retirado en. Yuste, había aconsejado a Felipe II política de mano dura frente a la herejía. Los autos de fe de 1559, el Indice.inquisitorial del mismo año y la prohibición de estudiar en universidades extranjeras habían manifestado a la vez el rigor represivo y el recelo. El ascetismo espontáneo, la ortodoxia más estrecha y el temor a la opinión dominante imponían un vivir adusto y cohibido. Fray Luis lucha en una sociedad que se cierra. Aunque la Inquisición lo absuelva, los cinco años de cárcel y proceso reducen para mucho tiempo el campo de actividades en que, sin riesgos, podría ejercitarse el pensamiento español. Triste, dramática España de Felipe II. Bien es verdad que el panorama de la Europa contemporánea no era más sonriente: guerras de religión, matanzas como las de Saint Barthélemy, persecución de la minoría vencida en nombre del credo vencedor en cada país. Católicos y reformistas réchazan para su indumentaria los colores vivos: Europa entera se viste de negro. La grandeza de Fray Luis consiste en haber superado este ambiente impulsando con entusiasmo y fervor cuanto podía ser punto de partida para la elevación espiritual, y rebelándose con firme desafío — «ab ipso ferro»- contra lo que era constricción anuladora. 
Encuadrados así los dos poetas en sus respectivos momentos históricos, examinemos el modo de tratar cada uno el tema del "Beatus ille " horaciano, que Garcilaso toca en su Égloga II, vv. 38-76:

¡Cuán bienaventurado

aquél puede llamarse

que con la dulce soledad s'abraza.

y vive descuidado

y lejos d' empacharse

en lo que al alma impide y embraraza!

No ve la llena plaza

ni la soberbia puerta

de los grandes señores,

ni los aduladores

a quien la hambre del favor despierta;

no le será forzoso

rogar, fingir, temer y estar quejoso.

A la sombra holgando

d'un alto pino o roble

o d'alguna robusta y verde encina,

el ganado contando

de su manada pobre

que en la verde selva s'avecina,

plata cendrada y fina

y oro luciente y puro

bajo y vil le parece,

y tanto lo aborrece

que aún no piensa que dello está seguro,

y como está en su seso,

rehuye la cerviz del grave peso.

Convida a un dulce sueño

aquel manso ruido

del agua que la clara fuente envía,

y las aves sin dueño,

con canto no aprendido,

hinchen el aire de dulce armonía.

Háceles compañía

a la sombra volando 


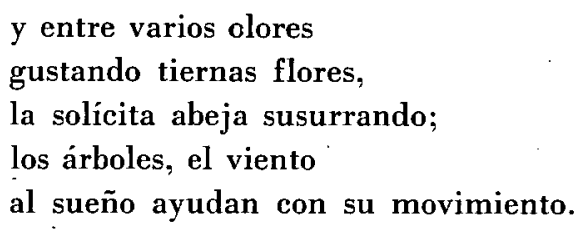

La soledad aparece en la poesía. de Garcilaso con dos aspectos distintos, casi contradictorios. Hay de una parte la soledad del melancólico, deseoso de apartamiento para ensimismarse en sus dolores. Como Petrarca en su célebre soneto «Solo e pensoso i più deserti campi / vo mesurando a passi tardi e lenti", y como el caballero "lastimado de tristura" que en un romance de Juan de la Enzina se pierde entre montañas, "por unos puertos arriba", Garcilaso se presenta así en el comienzo de la canción II:

La soledad siguiendo; rendido a $\mathrm{mi}$ ventura, me voy por los caminos que se ofrecen...

Pero hay también la soledad del humanista, la que para Fernán Pérez de Oliva, en su Diálogo de la dignidad del hombre, era "una que mucho amo»: ésta es la que el pastor Salicio alaba en la Égloga II. Horacio había hablado de alejamiento respecto a la ciudad y sus enojosos tratos - procu.l n e.goti is - sin llegar a una busca tan afanosa e ilusionada de la soledad como los enamorados de ella en la primera.mitad del siglo XVI. Según nos dice Garcilaso, el que logra abrazarse con la soledad queda libre, sí, de preocupaciones e inquietudes, como en el epodo del venusino ( $y$ vive descuidado); pero también desliga su alma de impedimentos (y lejos de empacharse / en lo que el alma impide y embaraza). El poeta señala cuáles son los obstáculos que se oponen a que el alma pueda realizarse a sí misma: en primer lugar la ambición de poder, representada por la llena plaza, el foro romano donde los oradores arengaban a la multitud y donde se dirimíar, los pleitos. Otra barrera son las pretensiones cortesanas, experimentadas y padecidas por quien, después de servir años y años a Carlos V, había caído en su desgracia: la soberbia puerta / de los grandes señores no es mero recuerdo de los $\mathrm{supe} r \mathrm{ba}$ civium / potentiorum limina horacianos, sino 
realidad penosamente vivida. También conocía. Garcilaso el proceder de los aduladores / a quien la hambre del favor despierta, y seguramente habría dicho de ellos como de-los codiciosos en la elegía a Boscán: «un poco más que aquellos me levanto". Escarmentado tras el confinamieñto en la isla del Danubio, el cortesano humanista cifra la beatitud del solitario en que no le será forzoso / rogar, fingir, temer y estar quejoso. La soledad permite ser dueño de sí y alcanzar una serenidad digna.

La libertad respecto del mundo libera también de las necesidades materiales. Nos lo dice la segunda estrofa: Salicio se contenta con la pobreza. La rústica sencillez encomiada por el usurero horaciano es aquí mundo pastoril idílico; sus venturas se limitan a holgar a la sombra de los árboles y contar las ovejas de su pequeño hato. Tan simple felicidad permite despreciar riquezas: plata cendrada y fina, y oro luciente $y$ puro / bajo y vil le parece; pero este desdén es un procedimiento para eludir otra cautividad temible: $y$ tanto lo aborrece / que aun no piensa que dello está seguro, y como está en su seso, rehuye la cerviz del grave peso.

Ya en esta segunda estrofa apunta la visión de una naturaleza perfecta. Cada sustantivo referente a una realidad natural lleva el epíteto característico de la cualidad que más lo acerca a la perfección de su arquetipo: "alto pino o robre", "robusta y verde encina", "verde selva". Las cosas se elevan platónicamente hacia sus respectivas ideas. La tercera estrofa se destina en su totalidad a la contemplación y goce de esta naturaleza quintaesenciada: «dulce sueño», "manso ruido», «clára fuente», "dulce armonía», «tiernas flores», "solícita abeja». Garcilaso pondera que el canto de las aves es natural, innato, "no aprendido», y que las aves cantoras son libres, «sin dueño», como el solitario que, horro de ambición y avaricia, deleita su vista y su oído - los "sentidos mejores", según don Luis de Góngora-, y comprende el placer de la abeja al oler las flores y libar su néctar.

La versión garcilasiana del "Beatus ille» selecciona el contenido de su modelo. Rechaza la ironía de que la alabanza de la vida campestre surja en boca de un usurero. Sustituye 
las tareas agrícolas - propias de villanos, no de caballerospor el bucolismo arcádico que la literatura de las generaciones inmediatas había resucitado en España e Italia como ficción socialmente aceptada. Junto a la complacencia sensorial de Horacio ante la naturaleza, refleja también el sentir virgiliano de ella, más hondo y delicado, así como el platonismo renacentista que la idealiza. Pero, sobre todo, el hedonismo del poema horaciano queda superado en las estancias de Garcilaso: la soledad es aquí deseable y deseada porque hace que el alma se sienta dueña de sí, libre y serena.

Tres poemas de Fray Luis se relacionan con el tema del "B e a t u s - ille». El más antiguo es la célebre oda da la $V i$ da retirada, llamada también Canción a la vida solitaria en algunos manuscritos. En uno de la Biblioteca del Palacio Real, que ofrece la versión presumiblemente primigenia, con un total de doce liras en vez de las diecisiete que figuran en los demás, lleva como título "Desprecio del mundo. Al recogimiento de Carlos Quinto». Sea o no autógrafo su texto del poema, no lo es ese título, escrito con letra muy distinta. Si le diéramos crédito, la fecha inicial de la oda sería el año 1556, en que el Emperador se retiró a Yuste; pero en general los críticos se resisten a admitir que el poema se compusiera con tal motivo, dado su fuerte acento personal. De todos modos se considera obra de época relativamente temprana dentro de la producción de Fray Luis; incluso la versión con cinco estrofas añadidas parece ser anterior al proceso inquisitorial de 1572-1576 ${ }^{1}$, aunque después pudo experimentar nuevos retoques.

Fray Luis no sólo tiene en cuenta el precedente de Horacio, sino también el de Garcilaso, de quien recoge el cantar «no aprendido" de las aves y el "manso ruido", aunque para un poeta sea el del agua y para otro el de los árboles al moverse. Ahora bien, la naturaleza que describe Fray Luis no está formada por entes quintaesenciados, sino por «maravillas concretas»-como diría Jorge Guillén- de la realidad: el huerto plantado por su mano, la fuente que lo atraviesa y que el

(1) Véanse, entre otros, Federico DE Ovis, Sobre la transmisión de la obra literaria de Fr. Luis de León, RFE, II, 1915, 217-257, y Oreste MACrí, La poesía de Fray Luis de León, Salamanca, Edic. Anaya, 1970, 297 y sigts. 
autor, infundiéndole alma, presenta apresurada y codiciosa por contemplar la hermosura del huerto y aumentarla con la suya propia. Ante la belleza natural el sentimiento se arrebata en exclamaciones, que no sólo expresan el arrobamiento contemplativo, sino también la sensación de encontrarse amparado tras peligrosa fuga:

¡Oh campo, oh monte, oh río!

¡oh secreto seguro deleitoso!

Roto casi el navio

a vuestro almo reposo

huyo de aqueste mar tempestuoso.

Fray Luis ve en la soledad un refugio para el evadido y un puerto para el náufrago. En otros poemas lo dirá con mayor angustia o con más directa huella de experiencias recientes; pero ya aquí las dos imágenes aparecen con insistencia y ensombrecen la serenidad buscada. Mientras Salicio únicamente expresa temor ante las asechanzas de la codicia y sólo entonces emplea el verbo rehuir, Fray Luis, desde el primer momento habla de la huida del mundo como los Padres del yermo, aunque asocie a ellos el ejemplo de los filósofos antiguos, de los «sabios»:

¿Qué descansada vida

la del que huye el mundanal ruido

y sigue la escondida

senda por donde han ido

los pocos sabios que en el mundo han sido!

«El mundanal ruido» es vanidad, estorbo para el alma y, sobre todo, peligro. Quien escapa de él halla en el compo su seguro, como el perseguido que se acoge al sagrado de una iglesia. Tal seguro, además de procurar deleite, es secreto, en la doble acepción de 'apartado, recóndito' y de 'oculto a los otros hombres', como la escondida senda de los sabios. El mar tempestuoso, alegórico en la estrofa quinta, reaparece en sentido directo hacia el final del poema a propósito de los navegantes que arriesgan su vida buscando las riquezas indianas: Ténganse su tesoro / los que de un flaco leño se confían... Y Fray Luis cree necesario añadir una estrofa para realzar el 
pavor de la escena con detalles que impresionan los sentidos: crujido de maderos que se rompen, oscuridad, confusión, gritos de los náufragos que para salvarse arrojan al agua los bienes ganados con fatiga:

La combatida antena

cruje, y en ciega noche el claro día

se torna; al cielo suena

confusa vocería,

y la mar enriquecen a porfía.

Igual que para Garcilaso, la soledad significa para Fray Luis libertad respecto al mundo y respecto de sí mismo. Frente a los «cuidados graves» que acosan a «quien al ajeno arbitrio está atenido», quiere vivir consigo "libre de amor, de celo, / de odio, de esperanzas, de recelo». En estos dos versos matiza más que Garcilaso las pasiones y afectos perturbadores, que se acumulan y contrastan reflejando la inquietud anímica del que anda «desalentado / con ansias vivas, con mortal cuidado». También hay acumulación en los adjetivos, que se agolpan al señalar la meta anhelantemente deseada: «un día puro, alegre, libre quiero". Destaquemos, porque la encontraremos en otros poemas, el ansia de pureza, hermana de la limpieza del corazón que no siente envidia: "Que no le enturbia el pecho / de los soberbios grandes al estado». Asimismo reclama atención la presencia del verbo querer, insistentemente repetida en otros pasajes: "No quiero ver el ceño / vanamente severo / de a quien la sangre ensalza o el dinero»; "Vivir quiero conmigo, / gozar quiero del bien que debo al cielo». Es que la serenidad pretendida está lejos de lograrse, y por eso aparece una y otra vez como objeto de voliciones que ora se expresan mediante el empleo de querer, ora mediante el subjuntivo optativo:

A mí una pobrecilla mesa, de amable paz bien abastada me baste; y la vajilla de fino oro labrada sea de quien la mar no teme airada.

.. Tendido yo a la sombra esté cantando. 
Volvamos al "Vivir quiero conmigo": en Fray Luis la serenidad ansiada se identifica con la vida interior; y ésta no consiste en orgullosa complacencia por el dominio de sí mismo, sino que implica reconocimiento de los beneficios recibidos de Dios: "gozar quiero del bien que debo al cielo». Aunque en esta oda se manifieste con menos insistencia que en otras de Fray Luis, es también esencial en ella el sentimiento religioso, que no aparece en la paráfrasis del «B e a t u s ill e» por Garcilaso. Tampoco hay en boca de Salicio referencias a la sabiduría; sí, por el contrario, en el maestro Fray Luis, tanto cuando habla de los pocos sabios que han seguido la vía del apartamiento, como en la última estrofa, donde suma al disfrute de la naturaleza la atención al ejercicio poético:

...Tendido yo a la sombra esté cantando.

A la sombra tendido, de hiedra y lauro eterno coronado, puesto el atento oído al son dulce, acordado, del plectro sabiamente meneado.

Ya el cultismo plectro conlleva el recuerdo de la antigüedad clásica, lo mismo que la corona inmarcesible, de viejo valor simbólico: en la frente de los doctos la hiedra era el premio con que Horacio esperaba igualarse a los dioses ( " $\mathrm{me}$ doctarum hederae praemia frontium / dis m i s c e n t s u per i s ", Carm., I, I, 29-30); el laurel era tradicional galardón de poetas. El hecho de que el varón solitario sueñe aquí ceñirse esa doble corona es muy significativo: estrofas antes, tras hablar de la indiferencia frente al poder y la riqueza, Fray Luis había agregado el desdén por la gloria mundana: su sabio «no cura si la fama / canta con voz su nombre pregonera» y equipara al viento el renombre ganado a costa de inquietudes: "¿Qué presta a mi contento / si soy del vano dedo señalado, / si en busca de este viento / ando desalentado...» Habremos de entender que la gloria literaria quedaba fuera de tal rechazo. Y esa excepción concuerda con la continua labor de lima y retoque a que Fray Luis sometió sus poemas, a pesar de llamarlos "obrecillas" que "en mi mocedad y casi en mi niñez se me cayeron como de entre las manos». 
La más antigua oda luisiana inspirada en el " B e a t u s ille» difiere ya de las estancias de Garcilaso en rasgos esenciales: 1) un sentimiento de la naturaleza más inmediato y personal; 2) la zozobra del vivir mundano se presenta más dramática, incluso angustiosa; 3) el apartamiento se convierte en sagrado del fugitivo y puerto de salvación para el náufrago; 4) se manifiesta un ansia de pureza, de corazón no enturbiado; 5) la religiosidad, apenas expresa, marca sin embargo el hito supremo de la obra; y 6) hay evidente conciencia de «letrado», de poeta sabio con afán de gloria imperecedera por sus creaciones. 